\title{
Performance of a novel vertical-flow settler: a comparative study
}

\author{
ZHANG Zhong-guo, CHEN Zhao-yang, LI Yan-zhong, FAN Jing-hua, FAN Bin, LUAN \\ Zhao-kun*, LU Dao-qiang \\ (State Key Laboratory of Environmental Aquatic Chemistry, Research Center for Eco-Environmental Sciences, Chinese Academy of Sciences, Beijing \\ I00085, China. E-mail: luanzk@rcees.ac.cn; cn.zhang@163.com)
}

\begin{abstract}
By increasing particle concentration and $G$ value (root-mean-square velocity gradient) to enhance flocculation, a novel vertical-flow settler was designed to increase sedimentation effectiveness, and to simultaneously improve operational stabilization. Due to the gradual decrease in upward flow-rate of raw water, a flocs blanket would form and suspend in the middle section of the settler, not at the bottom as in a conventional clarifier. Enough large flocs, resulted from flocculation or filtration, would continuously settle out of the flocs blanket, and simultaneously, the flocs in raw water or those forming above the blanket would ceaselessly enter the flocs blanket. As a result, the flocs concentration in the blanket could keep a dynamic balance. The hydrodynamic shear in the blanket was improved by flow separation, which was induced by the abrupt change in flow channel. Due to the flocs blanket and improved hydrodynamic shear, flocculation would be enhanced, which was helpful for removing fine particles in raw water. A comparative study showed that the novel vertical-flow settler had a much better performance in the removal of the particles in raw water than a conventional one, when they treated kaolin suspensions of different concentrations $(500,100 \mathrm{and} 50 \mathrm{mg} / \mathrm{L}$, respectively) coagulated by polyaluminum chloride(PACl) at the up-flow rates of 1 and $2 \mathrm{~mm} / \mathrm{s}$, respectively.
\end{abstract}

Keywords: vertical-flow settler; settling tank; flocs blanket; coagulation; flocculation; $\mathrm{PACl}$

\section{Introduction}

Settling, usually following coagulation or biological degradation unit, is an important solidliquid separation process in water and wastewater treatment. It can be broken down into four types, namely settling of discrete particles, flocculation settling, hindered or zone settling, and compression settling (AWWA, 1999). The last two kinds of settling are issues of high concentration waste streams, which typically occur in secondary-settling tanks and sludge-handling devices or industrial applications. The first two types of settling representatively take place in suspension of low concentration, which is of the most concern with respect to the design of settler. As flocculation occurs during the settling of particles, the mass and size of particles will increase, and accordingly the settling is enhanced.

People have designed various settlers to satisfy the requirements in different situations. These settlers are different in many aspects, such as inlet manner, flow pattern, sedimentation efficiency, application field, and adaptability to fluctuations in raw water quality. A horizontal-flow settling tank is well adapted to the fluctuations in water quality, but requires a vast footprint. A radial-flow settler has a good performance, yet costs too much. A settler with packing, such as the inclined plate or tube settler, performs very well, takes a small projective area, while simultaneously has some defects, such as complex structure, high cost, and inconvenience for sludge discharging. A vertical-flow settler, which has been widely used in middle- or small-scale water and wastewater treatment plants, can be used not only as primary settler, but also as secondary settler. Although its sedimentation efficiency is generally lower than that of the settler with packing, its structure is much simple and is convenient for discharging sludge. Especially, it may be integrated with coagulation unit, where total footprint will greatly decrease.

In order to improve settling performance, various means were proposed and adopted, essentially including: (1) to increase settling area and to decrease settling height based on the principle of so-called shallow sedimentation proposed by Hazen, such as in the inclined plate or tube settler; and (2) to enhance flocculation such as in a clarifier, where the concentrated flocs form a blanket to remove particles in raw water.

For the vertical-flow settler, one of the successful improvements was the double- $V$ compartment vertical-flow settler (Villiers, 1961; Soutar, 1977), where the settling performance was improved by the enhanced flocculation induced by increasing the concentration of particles, or done by so-called "dynamic filtration": the solids in suspension were filtered through a stable flocs blanket. It was found that the settler, working at or near its maximum flow rate, produced an effluent of clarity better than that obtainable in quiescent settling for a comparable period of time (Villiers, 1961). The blanket stability was controlled by the settling velocity of the flocs and the up-flow rate of raw water (Gregory et al., 1996; Head et al., 1997), and its operational control was stringent to prevent the instability of the flocs blanket (Soutar, 1977; AWWA/ASCE, 1990). As treating high-turbidity raw water, the flocs blanket was rather unstable, and the flocs displayed very poor 
settleability (Chen et al., 2003).

In this paper, a novel vertical-flow settler, which possessed the merits of conventional vertical-flow settler, such as small projected area and convenience for discharging sludge, was designed to increase sedimentation efficiency by enhancing flocculation, and to simultaneously improve operational stabilization. A flocs blanket, which noticeably improved the rate of flocculation among particles, would form and suspend in the middle section of the novel vertical-flow settler, not at the bottom as in a conventional clarifier. Enough large flocs would continuously settle out of the flocs blanket, and simultaneously, the flocs in raw water or those forming above the blanket would ceaselessly enter the blanket. Accordingly, the flocs concentration in the blanket could keep a dynamic balance. Moreover, the hydrodynamic shear in the blanket was improved by the flow separation induced by the abrupt change in flow channel. Fine particles in raw water were removed by the enhanced flocculation induced by the flocs blanket and the improved hydrodynamic shear. The performance of the novel vertical-flow settler was investigated by a comparison with that of a conventional vertical-flow settler.

\section{Theories}

Based on the equations in Smoluchowski's flocculation model (Smoluchowski, 1917), a developed equation for expressing the rate of flocculation, $R$, between two particles of $i$ and $j$ can be given as (Thomas et al., 1999):

$$
R=\alpha \beta(i, j) n_{i} \mathrm{n}_{j}
$$

where $\alpha$ is the collision efficiency and represents the percentage of those collisions leading to attachment, $\beta$ $(i, j)$ is the collision frequency between particles of $i$ and $j$, and $n_{i}, n_{j}$ are the concentrations of particles of $i$ and $j$, respectively. This is the so-called curvilinear model, where the trajectory of one particle to approach another is curvilinear due to the actions of hydrodynamic interaction, van der Waals force, electrostatic repulsion, and so on. In rectilinear model, however, hydrodynamic interaction, van der Waals force, and electrostatic repulsion between two particles are not taken into account.

The collision efficiency, $\alpha$ (taking values from 0 to 1), is a function of the extent of particles destabilization: the greater the extent of destabilization is, the greater the value of $\alpha$ is (Thomas et al., 1999). Furthermore, according to Han and Lawler (1992), the collision efficiency is also influenced by the model of flocculation, i.e. perikinetic flocculation (induced by Brownian motion of particles), orthokinetic or shear flocculation (induced by hydrodynamic shear) or differential sedimentation (induced by the differences in the settling velocities of individual particles), the size ratio between two particles, and so on.
The collision frequency, $\beta(i, j)$, is a function of flocculation model. According to Smoluchowski (1917), Camp and Stein (1943), the collision frequency for shear-induced flocculation between two particles, $\beta_{\mathrm{sh}}(i, j)$, can be given as

$$
\beta_{\text {sh }}(i, j)=(G / 6)\left(d_{i}+d_{j}\right)^{3}
$$

where $G$ is the root-mean-square velocity gradient, $d_{i}$ and $d_{j}$ are the diameters of particles of $i$ and $j$, respectively. Eq.(2) shows that the collision frequency for shear-induced flocculation, namely orthokinetic flocculation, will increase with $G$ value and particles sizes. The $G$ value can be improved by the separation of boundary layer when the cross-section area of flow channel increases abruptly, as done in the novel vertical-flow settler. When both particles are greater than approximately $1 \mu \mathrm{m}$ in diameter and fairly similar in size (bigger than 0.1 in size ratio of smaller to larger), the predominant mechanism is orthokinetic flocculation (Han and Lawler, 1992).

Besides increasing $G$ value, Eq. (1) implies that increasing particle concentration also can enhance the rate of flocculation, as founded by Casson and Lawer (1990). This has been adopted in the clarifier and the double-V compartment vertical-flow settler (Villiers, 1961; Soutar, 1977). The flocs blanket, which plays a crucial role in removing fine particles, is a typical example of increasing particles concentration, and was employed in the novel vertical-flow settler. It should be noted that the flocs blanket in the novel vertical-flow settler suspended in the middle section, not at the bottom as that in the conventional clarifier. In a vertical-flow settler, as we know, raw water flows upwardly, opposite to particle settling in direction. So these particles with lower settling velocity than the flow rate will upwardly flow together with raw water, unless they form enough large particles by flocculation with other particles. As the flow rate gradually slows down with expanding flow channel in the middle section of a vertical-flow settler, it is possible that much more particles will stop flowing upwardly, and consequently form a flocs blanket, which will flocculate with most fine particles in raw water and remove them. Enough large particles will continuously settle out of the flocs blanket, and the flocs in raw water and those forming above the blanket will endlessly enter the flocs blanket. As a result, the flocs blanket can be maintained automatically at a certain of concentration. These settling particles will flocculate with the rising fine particles below the blanket, and the fine particles through the blanket will further flocculate each other above the blanket. Moreover, based on the theory proposed by Wilson et al. (1979), the eddies generated by the settling particles also will lead to collisions among particles and improve the removal of fine particles.

Based on these methods on enhancing coagulation as discussed above, a novel vertical-flow settler 
(Fig.1a) was designed. In this settler, some flocs would stop flowing upwards with raw water in the flocs blanket zone due to the gradual decrease in flow rate of raw water, and at the same time, the large flocs forming by flocculation in the settling zone I would settle down and finally suspend in the flocs blanket zone because of the high flow rate in the settling zone II. As a result, a flocs blanket would form in the flocs blanket zone. Moreover, $G$ value would increase because of flow separation induced by the abrupt change in flow rate near the boundaries between the settling zone I, II and flocs blanket zone, respectively. All these will enhance flocculation, and consequently improve settling performance. It should be noted that mechanical filtration is also play an important role in the removal of fine particles in the flocs blanket (Gregory et al., 1996).

\section{Experimental}

\subsection{Preparation of PACl coagulant solution}

Polyaluminum chloride ( $\mathrm{PACl}$ ) was used as coagulant in this study. A commercial liquid $\mathrm{PACl}$ (Tianjin Dagang Chemical Plant, China), labeled with $\mathrm{Al}_{2} \mathrm{O}_{3}$ content as $16 \%$ and $\mathrm{OH} / \mathrm{Al}$ ratio as 2.1 , was diluted by deionized water to a concentration of $1 \%$ $(\mathrm{v} / \mathrm{v})$ a day prior to every set of experiments, to avoid ageing phenomena and improve reproducibility (Rossini et al., 1999).

\subsection{Synthetic kaolin suspension}

A stock suspension of kaolin was prepared by dispersing kaolin in powder form (Beijing Xudong Chemical Plant, China; chemical grade) into deionized water to a concentration of $10 \mathrm{~g} / \mathrm{L}$. The experiment suspensions were prepared by diluting the stock suspension to a desired concentration. All used suspensions contained $1 \mathrm{mmol} / \mathrm{L}$ of $\mathrm{NaHCO}_{3}$ to provide alkalinity. The size distribution of the kaolin suspension, measured by Mastersizer 2000 (Malvern Instruments Ltd., UK), was in the range of 0.275 to $39.8 \mu \mathrm{m}$, and with a mean volume diameter of 10.1 $\mu \mathrm{m}$.

\subsection{Coagulation experiments}

The primary purposes of coagulation experiments were to evaluate the optimum coagulant dosage and to supply the settlers with kaolin suspension coagulated at the optimum coagulant dosage. All coagulation experiments were conducted at $(20 \pm 2)^{\circ} \mathrm{C}$. The initial $\mathrm{pH}$ value of all suspensions used was $7.5 \pm 0.1$, adjusted by hydrochloric acid and sodium hydroxide. All coagulation experiments were conducted with the same coagulation mixer (Model JTY, Daiyuan Comp. Ltd., Beijing, China). The coagulation vessel was a $1-\mathrm{L}$ cylindrical container with an inner diameter of $105 \mathrm{~mm}$. The mixing was provided by a $50 \times 40(\mathrm{H} \times$ W) $\mathrm{mm}$ flat rectangular blade centrally located $15 \mathrm{~mm}$ above the base of the container. The rotate speed of the blade was adjustable. The experiments to optimize coagulation dosage involved rapid mixing $\left(G=350 \mathrm{~s}^{-1}\right.$, 2 min $)$, slow mixing $\left(G=15 \mathrm{~s}^{-1}, 10 \mathrm{~min}\right)$ and sedimentation $(30 \mathrm{~min})$. Following sedimentation, a $25-\mathrm{ml}$ sample was taken from $50 \mathrm{~mm}$ below the water level for residual turbidity measurement (Turbidimeter $2100 \mathrm{~N}$, Hach Chemical Comp., USA). At the end of rapid mixing, a 5-ml sample was taken for zeta potential measurement (Zetasizer 2000, Malvern Instruments Ltd., UK). The experiments for supplying the settlers with suspension involved merely rapid mixing ( $\left.G=350 \mathrm{~s}^{-1}, 2 \mathrm{~min}\right)$ and slow mixing $\left(G=15 \mathrm{~s}^{-1}\right.$, $10 \mathrm{~min}$ ).

\subsection{Settling experiments}

A schematic diagram of the novel vertical-flow settler is showed in Fig. Ia. The main difference between the novel and the conventional (Fig.lb) settlers was that in the former, there was a flocs blanket zone which divided the settling zone into two parts, settling zone I and settling zone II, but in the latter, there was no flocs blanket zone and only one settling zone. Both settlers were made of organic glass, and had the same valid volume of $820 \mathrm{ml}$ to ensure the same hydraulic residence time at the same up-flow rate (in this study, the up-flow rates refer to those in the settling zone I of the novel settler or in the settling zone of the conventional settler). In the novel settler, the inner diameters of the settling zone I and II were respectively $40 \mathrm{~mm}$ and $25 \mathrm{~mm}$, and the inclined angle of the cone-shaped surface in the flocs blanket zone was $75^{\circ}$. The inner diameter of the settling zone in the conventional settler was $40 \mathrm{~mm}$.
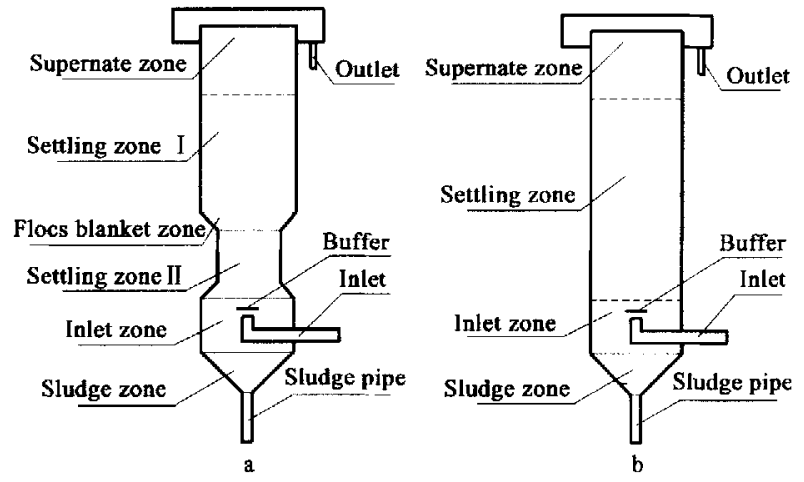

Fig. 1 Schematic descriptions of the novel (a) and the conventional (b) vertical-flow settlers used in the study

A semi-continuous experiment was carried out, as shown in Fig.2. The coagulated kaolin suspension was added into the feed tank (capacity of $5 \mathrm{~L}$ ), and then was fed into the novel or conventional vertical-flow settler by a peristaltic pump (Model SYB-Z, Beijing Qingyun Instrument Plant, China). The flow rate was monitored by a rotameter. The suspension in the feed tank was controlled with a volume of $4-5 \mathrm{~L}$, and mixed gently to keep flocs in suspension. From the onset of the experiment, $25 \mathrm{ml}$ samples were taken from the outlets of both settlers at a desired time for turbidity measurements. 


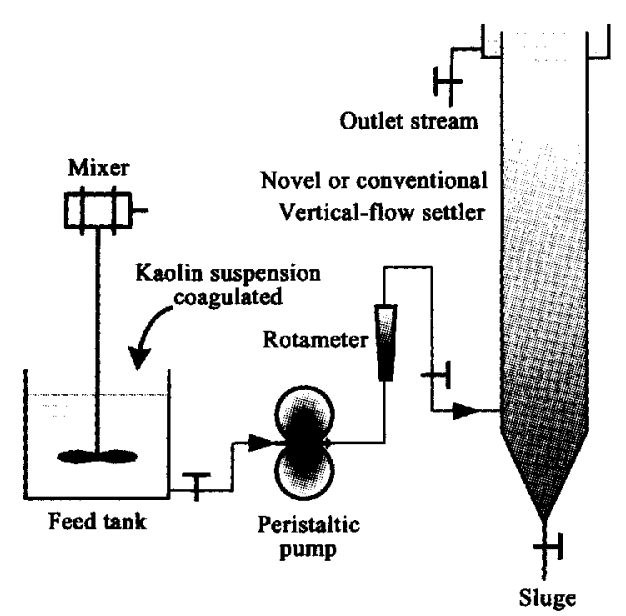

Fig.2 Schematic chart of the settling experiments

\section{Results and discussion}

\subsection{Determination of PACl dosage for the coagu- lation of kaolin suspensions}

Kaolin suspensions of three different concentrations, namely high- $(500 \mathrm{mg} / \mathrm{L})$, medium- $(100$ $\mathrm{mg} / \mathrm{L})$ and low-concentration $(50 \mathrm{mg} / \mathrm{L})$, were investigated. The results are shown in Fig.3. With the increase in $\mathrm{PACl}$ dosages, the zeta potentials of kaolin particles in suspensions continued to increase until $\mathrm{PACl}$ was no more dosed, and simultaneously, the residual turbidities continued to decrease, which was similar to that observed by Kan et al. (2002). At last, the zeta potentials increased to around zero, and the residual turbidities correspondingly decreased to the lowest values. The lowest values of residual turbidities corresponding to kaolin suspensions of high-, medium- and low-concentration were 3.00, 4.74 and 4.80 NTU, respectively. The optimal PACl dosages in

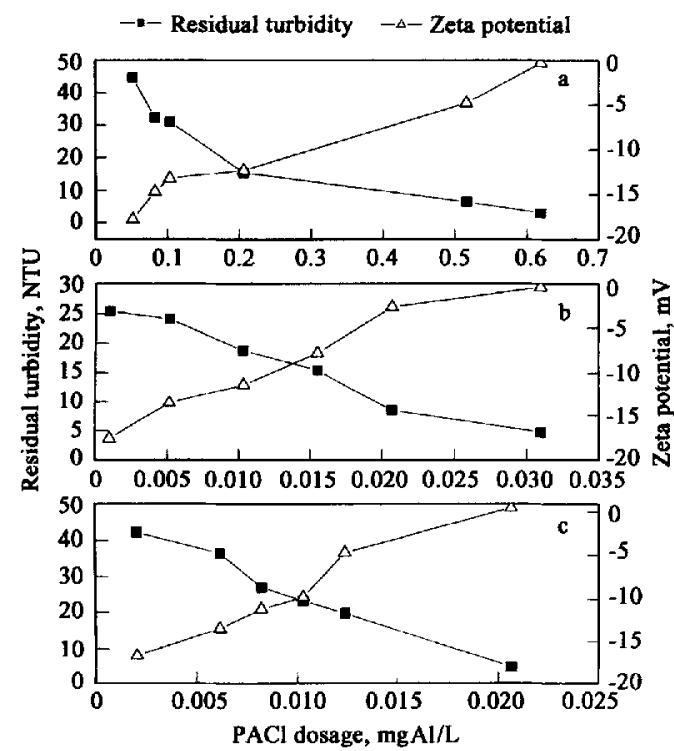

Fig. 3 Effect of $\mathrm{PACl}$ dosages on the residual turbidity and the zeta potential of the kaolin suspensions

Kaolin suspension conc. $500 \mathrm{mg} / \mathrm{L}(\mathrm{a}), 100 \mathrm{mg} / \mathrm{L}$ (b) and $50 \mathrm{mg} / \mathrm{L}$ (c); $T=(20 \pm 2)^{\mathscr{Q}} \mathrm{C}$; initial $\mathrm{pH}=7.5 \pm 0.1$ regard to the residual turbidities were $0.62,0.03$ and $0.02 \mathrm{mg} / \mathrm{L}$ as $\mathrm{Al}$, respectively. The zeta potentials around zero indicated that the predominant coagulation mechanism at the optimal PACl dosages was charge neutralization. Letterman et al. (1982) and Dentel (1988) found that the amount of coagulant needed to bring the zeta potential of particles to zero would increase with the increase in the surface area of all particles in suspension. So the $\mathrm{PACl}$ dosage required to neutralize the surface charge increased with the concentration of kaolin particles in the suspension. At constant $\mathrm{pH}$, the restabilization of kaolin particles and sweep flocculation would possibly occur sequentially if continue to increase the dosage of $\mathrm{PACl}$ in this study, based on the research by Letterman et al. (1982).

\subsection{A comparative study on settling performance}

\subsubsection{Residual turbidities of outlet streams}

Fig.4a shows the residual turbidities versus time in outlet streams from both settlers when the kaolin suspension of high-concentration $(500 \mathrm{mg} / \mathrm{L})$ was treated at the up-flow rates of 1 and $2 \mathrm{~mm} / \mathrm{s}$, respectively. The novel settler obviously excelled the conventional settler in the residual turbidities at both

-- Conventional vertical-flow settler, up-flow rate of $2 \mathrm{~mm} / \mathrm{s}$

$\rightarrow-$ Novel vertical-flow settler, up-flow rate of $2 \mathrm{~mm} / \mathrm{s}$

- Conventional vertical-flow settler, up-flow rate of $1 \mathrm{~mm} / \mathrm{s}$

$\rightarrow-$ Novel vertical-flow settler, up-flow rate of $1 \mathrm{~mm} / \mathrm{s}$
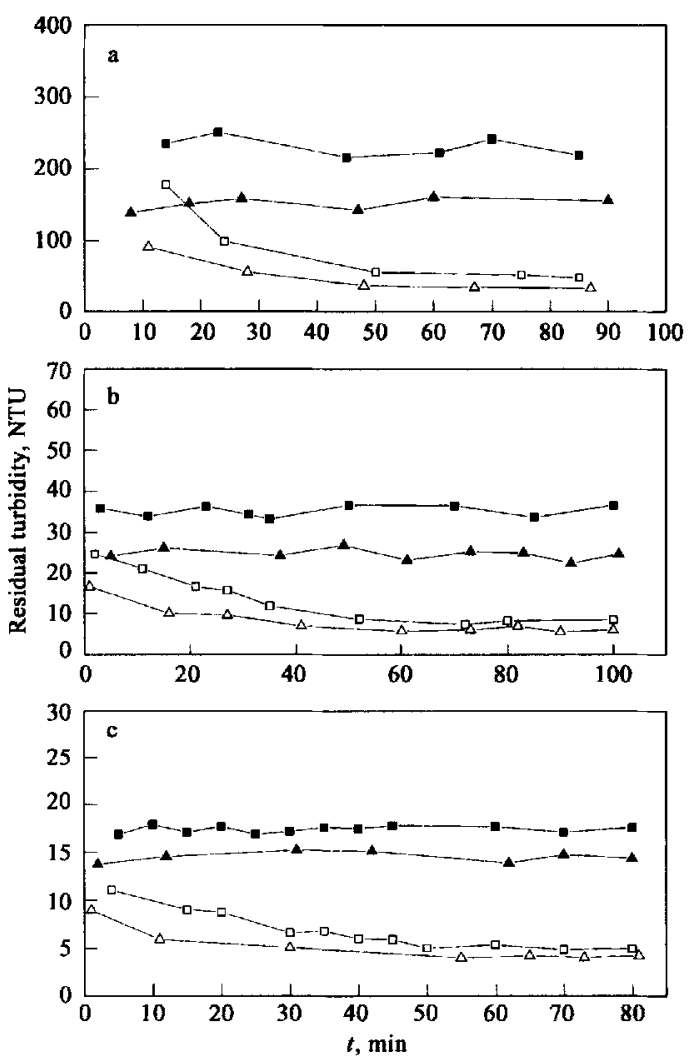

Fig.4 Comparison of the residual turbidities in the outlet streams of both settlers treating various kaolin suspensions (a. $500 \mathrm{mg} / \mathrm{L}$; b. $100 \mathrm{mg} / \mathrm{L} ; \mathrm{c} .50 \mathrm{mg} / \mathrm{L}$ ) coagulated by $\mathrm{PACl}$ at different up-flow rates $T=(20 \pm 2)^{\circ} \mathrm{C}$; initial $\mathrm{pH}=7.5 \pm 0.1$; PACl dosages: a. 0.62 $\mathrm{mg} / \mathrm{L}$, b. $0.03 \mathrm{mg} / \mathrm{L}$, and c. $0.02 \mathrm{mg} / \mathrm{L}$ as $\mathrm{Al}$ 
up-flow rates. The residual turbidities in the novel settler gradually decreased by time at the initial stage, but those in the conventional settler generally did not decrease by time. In the novel settler, the large flocs forming by flocculation in the settling zone $I$ would continually settle, and most of them would suspend in the flocs blanket zone due to the high up-flow rate in the settling zone II. As a result, the concentration of the flocs in the flocs blanket zone would increase with time at the initial stage, which would lead to gradual increase in the rate of flocculation in terms of Eq. (1). Simultaneously, some of the flocs up-flowing from the settling zone II would also suspend in the flocs blanket zone and lead to the increase in flocs concentration because of flocculation or mechanical filtration. A flocs blanket would finally form in the novel vertical-flow settler, as shown in Fig.5a. In the conventional settler, however, the large flocs forming by flocculation in the settling zone would settle to the bottom of the settler, and so flocs blanket would not form, as shown in Fig. 5 b. As the flocs concentration in the blanket was constant, the rate of flocculation and the residual turbidities generally did not change over time. Fig.4a also shows that the residual turbidities at the high flow rate $(2 \mathrm{~mm} / \mathrm{s})$ were higher than those at the low flow rate $(1 \mathrm{~mm} / \mathrm{s})$, consistent with those predicted by a model proposed by Head et al. (1997), which gave a good prediction for a water treatment plant. The reasons are that the number of the particles with the settling rate lower than the up-flow rate of water was much more at the high flow rate, and that the high flow rate shortened the hydraulic residence time of the suspensions. Besides, at the higher flow rate $(2 \mathrm{~mm} / \mathrm{s})$ in the novel vertical-flow settler, the flocs concentration in the blanket was lower, and simultaneously the interface height of the blanket was higher, as shown in Fig.6. At the initial stage, before the flocs blanket was formed, the novel settler also showed a better settling performance than the conventional settler, which was mostly due to the enhanced shear flocculation in the former.

The performance of the novel settler was also better than that of the conventional settler in the residual turbidities of outlet streams, when the kaolin suspensions of medium- (100 mg/L) or low-concentration $(50 \mathrm{mg} / \mathrm{L})$ were settled at the up-flow rates of 1 and $2 \mathrm{~mm} / \mathrm{s}$, as shown in Figs. $4 \mathrm{~b}$ and c. These further confirmed the conclusion that the performance of the novel settler was better than that of the conventional settler.

\subsubsection{Sedimentation efficiency}

Sedimentation efficiency can be used to evaluate the performance of a settler. It is defined as (Ziolo, 1996):

$$
\eta=\frac{c_{1}-c_{2}}{c_{1}}
$$

where $\eta$ is the sedimentation efficiency, and $c_{1}$ and $c_{2}$
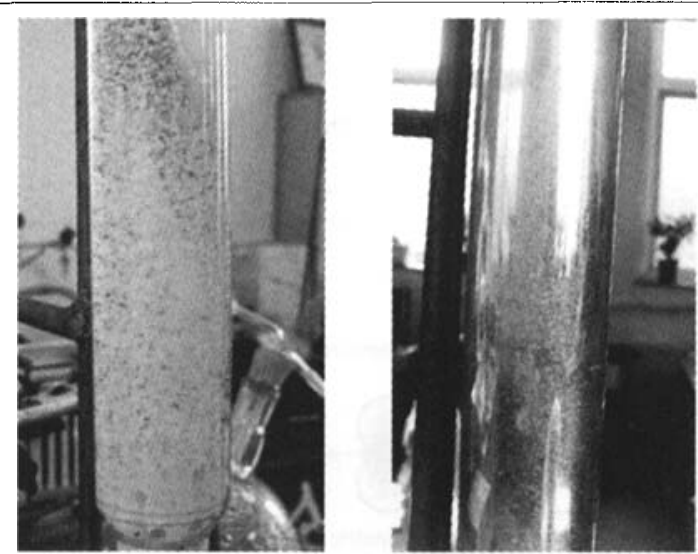

(a) Novel vertical-flow settler (b) Conventional vertical-flow settler Fig.5 Flocs behavior in novel and conventional vertical-flow settlers with the kaolin suspension of $100 \mathrm{mg} / \mathrm{L}$ coagulated by $\mathrm{PACl}$ at the up-flow rate of $2 \mathrm{~mm} / \mathrm{s}$
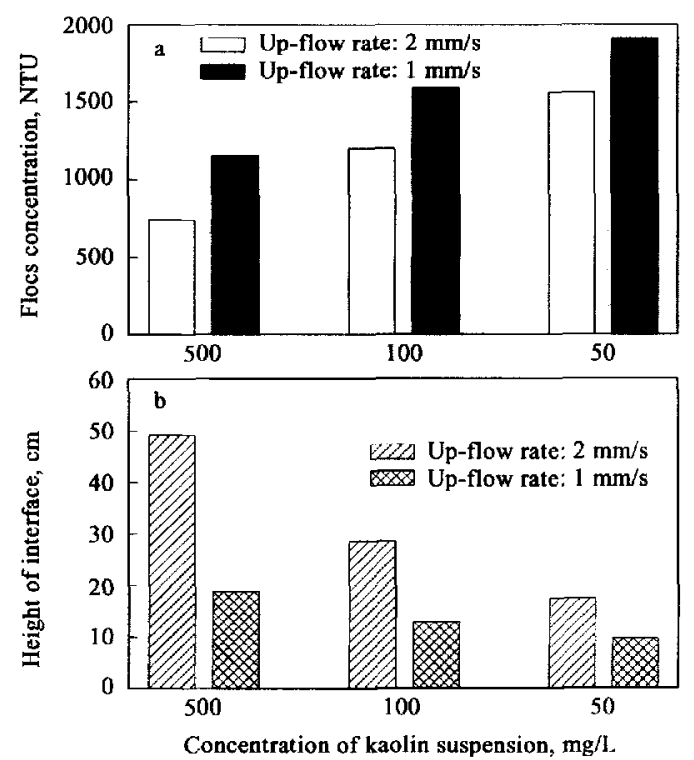

Fig.6 Flocs concentration and interface height in the flocs blanket in the novel vertical-flow settler at equilibrium

are the particles concentrations of the inlet and outlet streams $(\mathrm{mg} / \mathrm{L})$ for a settler, respectively.

For the kaolin suspension used in this study, there was a linear correlation between the suspension turbidities and the particle concentrations in the range of 0 to $500 \mathrm{mg} / \mathrm{L}$ (Fig.7). So for both settlers in this study, substitute respectively $c_{1}$ and $c_{2}$ in Eq. (3) with the turbidities of the inlet and outlet streams, the sedimentation efficiency could be obtained, which was shown in Fig.8. At the same flow rate, the sedimentation efficiency of the novel vertical-flow settler was higher than that of the conventional vertical-flow settler whether high-, medium- or low-concentration of kaolin suspensions were treated. At the flow rate of $1 \mathrm{~mm} / \mathrm{s}$, the sedimentation efficiency for the conventional and the novel settlers was 0.60 and 0.86 , respectively. At the flow rate of 2 $\mathrm{mm} / \mathrm{s}$, the sedimentation efficiency for the conventional and the novel settlers was 0.45 and 0.79 , 
respectively. The difference in the sedimentation efficiency between both settlers was more significant at higher flow rate. The reason was that in the novel settler, the enhanced flocculation induced by the flow separation and the concentrated flocs blanket, to a certain extent, offset the effect of insufficient hydraulic residence time, which had a remarkable effect on the conventional settler, as observed by Demir (1995). Fig.8 also shows that the sedimentation efficiency at the high flow rate $(2 \mathrm{~mm} / \mathrm{s})$ were higher than those at the low flow rate $(1 \mathrm{~mm} / \mathrm{s})$, correspondingly to the residual turbidities at various flow rate shown in Fig.4.

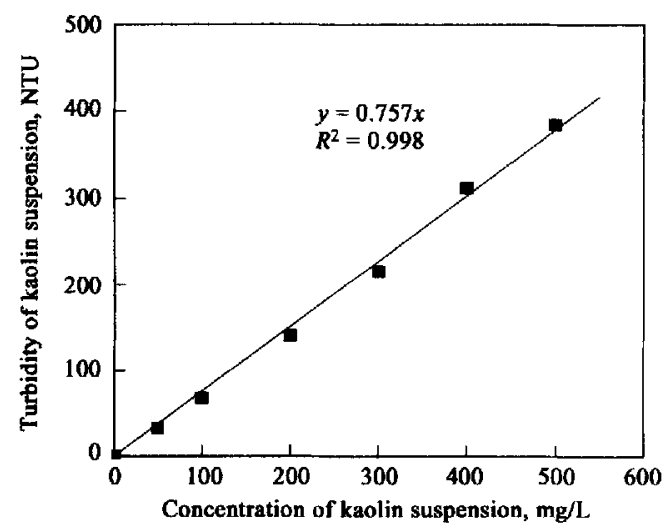

Fig.7 Correlation of the concentration and the turbidity of the kaolin suspension used in the study

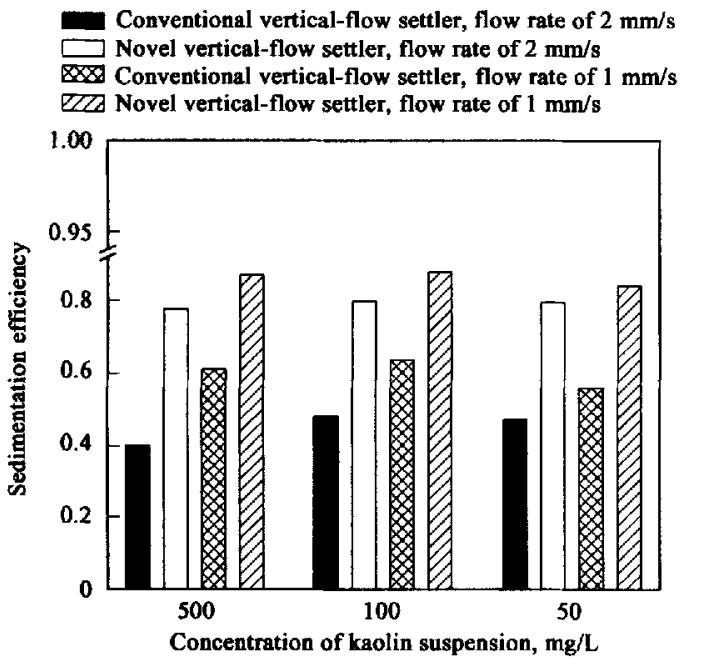

Fig.8 Comparison of the sedimentation efficiency for both settlers treating the kaolin suspensions of various concentrations at different up-flow rates. The experiment conditions were the same as those in Fig. 4

\section{Conclusions}

By increasing flocs concentration and $G$ value to enhance flocculation, a novel vertical-flow settler was designed to improve settling effectiveness. A flocs blanket would form and suspend in the middle section of the novel vertical-flow settler, not at the bottom as that in a conventional clarifier. The flocs concen- tration in the blanket could keep a dynamic stable. A comparative study between the novel vertical-flow settler and a conventional vertical-flow settler showed that the former had a better performance in the removal of the particles in suspension and sedimentation efficiency than the latter, when they treated the kaolin suspensions of different concentrations (500, 100 and $50 \mathrm{mg} / \mathrm{L}$, respectively) coagulated by $\mathrm{PACl}$ at the up-flow rates of 1 and $2 \mathrm{~mm} / \mathrm{s}$, respectively. At the flow rate of $1 \mathrm{~mm} / \mathrm{s}$, the sedimentation efficiency for the conventional and the novel settlers was 0.60 and 0.86 , respectively. At the flow rate of $2 \mathrm{~mm} / \mathrm{s}$, the sedimentation efficiency for the conventional and the novel settlers was 0.45 and 0.79 , respectively. All these showed that the novel vertical-flow settler was promising in increasing sedimentation efficiency. Certainly, a further study is necessary to optimize the geometry of the novel vertical-flow settler and to examine its operation in pilot or full scale.

\section{References:}

AWWA(American Water Works Association), 1999. Water quality and treatment - a handbook of community water supplies[M]. 5th ed. New York: McGraw-Hill.

AWWA/ASCE (American Water Works Association/American Society of Civil Engineerings), 1990. Water treatment plant design [M]. New York: McGraw-Hill.

Camp T R, Stein P C, 1943. Velocity gradients and internal work in fluid motion [J]. J Boston Soc Civ Eng, 30: 219-237.

Casson L W, Lawer D F, 1990. Flocculation in turbulent flow measurement and modeling of particle size distributions[J]. J Am Water Works Assoc, 82(8): 54-68.

Chen L C, Sung S S, Lin W W et al., 2003. Observations of bianket characteristics in full-scale floc blanket clarifiers [J]. Water Sci Technol, 47(1): $197-204$.

Demir A, 1995. Determination of settling efficiency and optimum plate angle for plated settling tanks[J]. Wat Res, 29(2): $611-616$.

Dentel S K, 1988. Application of the precipitation-charge neutralization model of coagulation[J]. Environ Sci Technol, 22(7): 825-832.

Gregory R, Head R, Graham N J D, 1996. Blanket solids concentration in floc blanket clarifiers[C]. Proc.: Gothenburg Symp. Edinburgh, UK.

Han M Y, Lawler D F, 1992. The (relative) insignificance of $G$ in flocculation[J]. J Ám Water Works Assoc, 84(10): 79-91

Head R, Hart J, Graham N J D, 1997. Simulating the effect of blanket characteristics on the floc blanket clarification process [J]. Water Sci Technol, 36(4): 77-82.

Kan C, Huang C, Pan J R, 2002. Time requirement for rapid-mixing in coagulation [J]. Colloids and Surfaces A: Physicochemical and Engineering Aspects, 203: 1-9.

Letterman R D, Vanderbrook S G, Sricharoenchaikit P, 1982. Electrophoretic mobility measurements in coagulation with aluminum salts[J]. J Am Water Works Assoc, 74(1): 44-51.

Rossini M, Garcia G J, Galluzzo M, 1999. Optimization of the coagulation- flocculation treatment: influence of rapid mix parameters[J]. Wat Res, 33(8): 1817-1826.

Smoluchowski M, 1917. Versuch einer mathematischen theorie der koagulationskinetik Kolloider Lösungen [J]. Z Phys Chem, 92 $129-168$.

Soutar B N, 1977. The design and operation of a double- $V$ compartment vertical-flow settler [J]. Journal of the South African Institute of Mining and Metallurgy, March: $163-174$.

Thomas D N, Judd S J, Fawcett N, 1999. Flocculation modeling: a review[J]. Wat Res, 33(7): 1579-1592.

Villiers $\mathrm{J} \mathrm{W}, 1961$. An investigation into the design of underground settlers [J]. Journal of the South African Institute of Mining and Metallurgy, June: $501-521$.

Wilson D J, Clarke A N, French R H, 1979. Theory of clarifier operation. IV . Orthokinetic flocculation in concentrated slurries [J]. Separation Science and Technology, 14(1): 1-12.

Ziolo J, 1996. Influence of the system geometry on the sedimentation cffectiveness of lamella settlers $[\mathrm{J}]$. Chemical Engineering Science, 51(1): $149-153$.

(Received for review November 14, 2005. Accepted January 6, 2006) 